\title{
Early intervention in elderly clients' health problems identified by home helps
}

\author{
Anette Hylen Ranhoff, MD, PhD \\ Department of Geriatric Medicine, Ullevaal Hospital, N-0407 Oslo, Norway \\ Address for correspondence: Department of Medicine, Ullevaal Hospital, N-0407 Oslo, Norway \\ Telephone +4722119100 Telefax +4722119181 e-mail anettehylen.ranhoff@ulleval.no
}

\begin{abstract}
Objective: To study the effect of early intervention in health problems identified by home helps.

Design: Open study with quasi-experimental design. Randomization took place at the level of the organizational units of home helps.

Setting: Community health services and a hospital-based general practice.

Subjects: Home help clients, 75 years or older, 113 in the intervention group and 161 in the comparison group.

Intervention: Home helps were trained to recognize signs of functional and mental impairment and asked to call the study doctor when new medical or functional problems were identified. The intervention lasted for two years with an additional year for observation.

Main outcome measures: Causes of referral, ICD-9 diagnostic categories, time under surveillance before long-term care or death, use of community services and hospital beds.

Results: 51 (45.1\%) of the intervention subjects were referred once or more often, 110 referrals in all. General loss of function was the most frequent cause, and in all but six referrals specific diagnoses were made. Home helps' referrals of patients with infection and stroke corresponded with the final diagnoses. After the first year of the study, the percentage of clients continuing to live at home was higher in the intervention group ( $\mathrm{P}=0.05$ after adjustment for baseline differences in age and gender), mortality was similar, and use of hospital beds higher in the intervention group.

Conclusions: Home helps can detect and communicate to a doctor functional decline and clinical manifestations of disease among their elderly clients. The study indicated, but provided no definite evidence, that direct referral from home helps to a hospital-based general practitioner can keep elderly people at home longer.
\end{abstract}

Key words: Home help; elderly; case-finding; general loss of function; long-term care; randomized controlled trial

\section{INTRODUCTION}

A significant proportion of old people have unreported health problems (1). Many studies of surveillance and case-finding in the elderly have demonstrated a benefit from geriatric services (2-5). The presentations of disease in old age are often nonspecific, with general loss of function and mental impairment being the most characteristic ones (1). To identify, at an early stage, elderly people with deteriorating health is important, though difficult (6).

Elderly recipients of home help are particularly frail (7-9). Many of them are cognitively impaired and may be unaware of symptoms and signs that should have caused them to see a doctor. Home helps spend more time with the elderly than any other health- and social workers do (10). In a nation-wide survey, $25 \%$ of persons 80 years and older had home help (7), and in the area for this study, $440(33.6 \%)$ out of 1,310 persons 75 years or older and living at home. We wanted to study whether a system of direct referral of the clients by the home helps to a hospital-based GP, working with the elderly, would improve the health services to elderly people living at home.

\section{MATERIALS AND METHODS}

The study took place between 1 October 1989 and 30 September 1992. All home helps employed by the local authorities were given a 10-hour course on presentations of disease in the elderly, i.e. edema, breathlessness, pain, and mobility problems. They were also 
trained to recognize functional impairment by systematic observation of activities of daily living (ADL) and mental functioning, using the Barthel ADL Index (11) and the Clinical Dementia Rating scale (CDR) (12). The Barthel index is intended to be scored by nurses or occupational therapists, but scorings made by non-professional assistants are reliable (13).

The study design is a combined single-nested/ double-nested experiment with randomization after stratification. Home helps were stratified on the basis of whether they were associated with a specific home district nurse $(n=35)$ or not $(n=26)$. Home helps not associated with a specific home district nurse were randomly allocated to the special intervention $(n=13)$ and to the comparison $(n=13)$ group. As a result, thirty-six of their elderly clients were nested in the special intervention group and 55 clients were nested in the comparison group (single-nested component). The remaining home helps were associated specifically (nested) with one of five home district nurses. For this group of home helps, randomization occurred at the district nurse level, with two of the five nurse districts randomized to the special intervention group and the remaining three randomized to the comparison group. This resulted in 14 home helps and their 77 nested clients being allocated to the special intervention group, and 21 home helps and their 106 nested clients being allocated to the comparison group (doublenested component). Combining the single- and doublenested components, there were 27 home helps and their 113 clients in the special intervention group and 34 home helps and their 161 clients in the comparison group.

All the clients were 75 years or older and lived in their own homes, but those belonging to one of the home district nurses lived in a block of flats with onsite home help and home nursing services ( 7 home helps and 38 subjects).

The home helps of the intervention group were instructed to refer the clients immediately over the telephone to the Out-patient Clinic for the Elderly when they observed a decline in ADL functioning or cognition, or were alerted by a client with new symptoms. The out-patient clinic was directed by a general practitioner (AHR) who had attended several courses in geriatric medicine. The doctor would then see the patient as soon as possible and preferably with a home visit, which is believed to provide more information about the functional level of the client than sessions at an out-patient clinic (14). Before seeing the patient, the study doctor discussed the reason for referral with the home help and categorized it. The final diagnoses were made in accordance with the International Classification of Diseases (ICD-9) (15). Existing resources in the health and social service sectors were used for intervention as indicated (e.g. hospitalization). Decisions about admittance to a nursing home were made independently of the study doctor, who had to apply on behalf of her patients. Date of death, admittance for long-term care in a nursing home, and use of hospital beds and community services were recorded.

\section{Statistical methods}

The principal study variable was the time under surveillance before admittance to a permanent place in an institution or death, whichever occurred first. Statistical analyses were carried out using the BMDP program package (16). Length of stay in hospital was analyzed after normalization by logarithmic transformation of the data.

\section{RESULTS}

\section{Background characteristics}

At the start of the study, mean age was 83.1 years in the intervention group and 81.7 years in the control group, and the difference between the means was significant ( 1.4 years, $95 \% \mathrm{CI}=0.2-2.6)$. There were $91(80.5 \%)$ women in the intervention group and 115 $(71.4 \%)$ in the comparison group, statistically insignificant before and after adjustment for differences in age.

\section{Causes of referral and resulting diagnoses}

In all, the home helps made 110 referrals to the study doctor for 51 persons $(45.1 \%$ of the subjects in the intervention group). The rate of referral in the various home help groups was not dissimilar, 0.61 (95\% CI = $0.43-0.76)$ in group I, $0.44(95 \% \mathrm{CI}=0.28-0.61)$ in group II, and $0.31(95 \% \mathrm{CI}=0.16-0.48)$ in the clients of the unorganized home helps. Of those referred, 25 were seen two to four times, and two were seen five times or more. In all, $104(94.5 \%)$ referrals resulted in a home visit, and two subjects were seen at the outpatient clinic. For four clients arrangements were made over the telephone. All were contacted by the study doctor within four days, and $89(80.9 \%)$ on the day of referral or the next day. Age of the referred subjects was significantly higher than of those never referred (mean 85.4 versus 81.2 years, difference between sample means $4.2,95 \% \mathrm{CI}=2.4-6.2$ ).

General loss of function, suspected infections, and mental symptoms and cognitive impairment were the most frequent causes of referral. The presenting problems and the resulting diagnoses are shown in Table 1. In $51(46.4 \%)$ referrals a new diagnosis was made, whereas in $59(53.6 \%)$ a deterioration of a previously diagnosed disease or disability was identified. Dementia, heart failure and malignancies were the most frequently diagnosed causes of general loss of function. The most prevalent diagnoses made were infectious diseases, mainly in the respiratory and urinary tract, heart failure and dementia. Twelve cases were referred for skeletal pain. Ten of these were classified as "other 
Table 1. Causes of referral and corresponding diagnoses ( $N=110$ referrals).

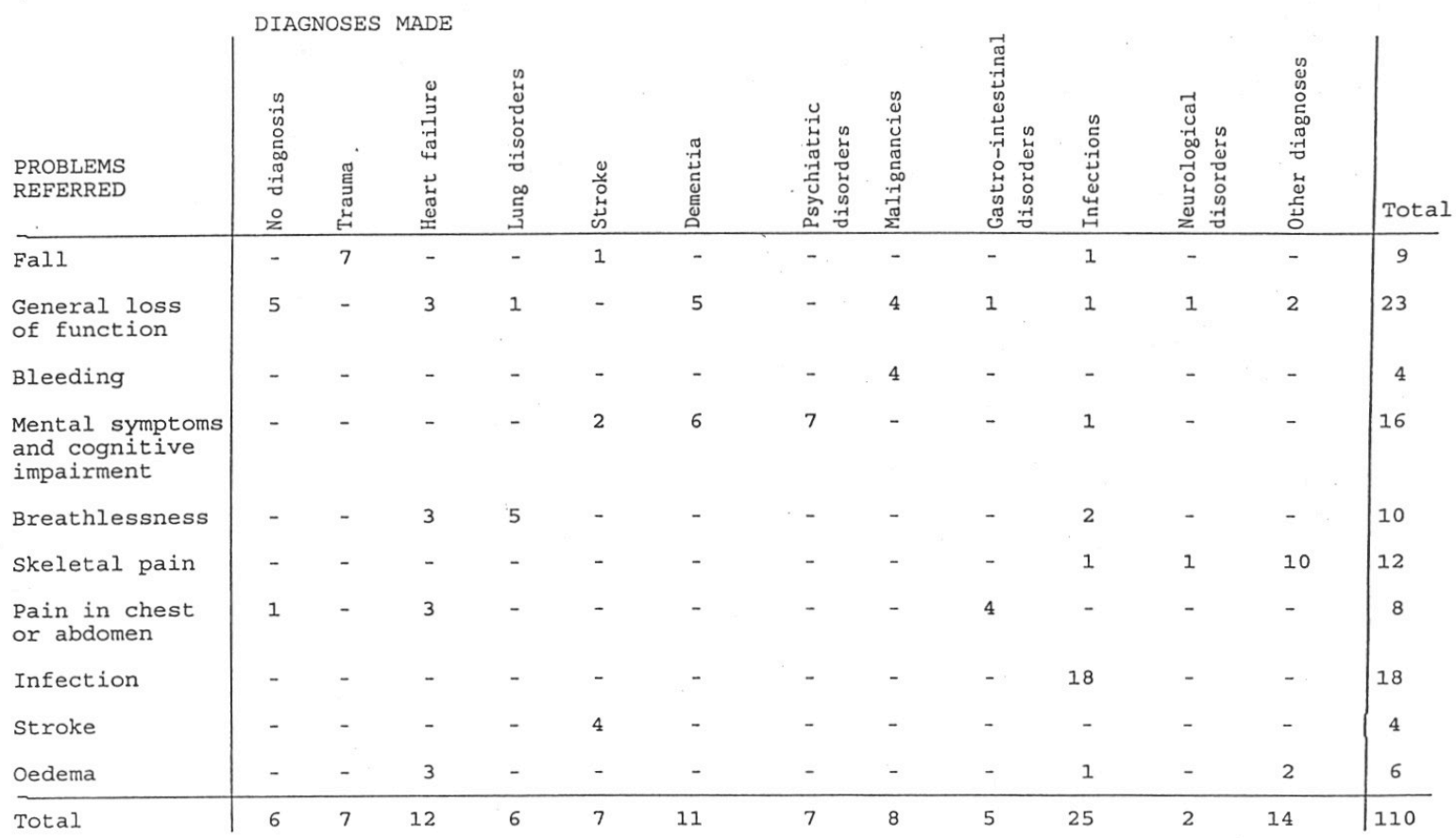

diagnoses", mainly osteoporosis and osteoarthritis. No specific diagnosis could be made in six referrals. The mean age of these subjects was higher than that of those with specific diagnoses made (mean 90.7 versus 84.8 , difference between sample means $5.9,95 \% \mathrm{CI}=$ 1.7-10.1).

\section{Types of intervention}

Drug treatment, mainly short courses of antibiotics, but also dosage adjustment and drug replacement, was the most frequent intervention initiated. Further referral was made for a wide range of supportive and caring services, e.g. home nursing, short-term and long-term stays in nursing homes, "meals on wheels", and transport support. Most of the cases, 86 (78.1\%), were treated by means of community health and social care resources alone, whereas $15(13.6 \%)$ were admitted to hospital and nine (8.2\%) were referred to specialists.

\section{Effects of intervention}

Figure 1 shows life table analysis of days on study before death or permanent placement in nursing home. At the end of the study, $59(52.2 \%)$ subjects in the intervention group were dead or in a long-term nursing home, while 54 were at home. In the comparison group, the figures were $83(51.6 \%)$ with 78 being at home. In the intervention group more subjects stayed at home during the first year of the study, and this difference nearly reached statistical significance $(\mathrm{P}=0.07)$. When adjustment had been made for differences between the groups in age and gender (using the Cox proportional hazards model), this difference proved to be statistically significant $(\mathrm{P}=0.05)$ (Table 2 ). The difference was confined to home help group I; when the subjects in this group were excluded from the analysis, no statistical difference appeared. At the end of study, the difference between the intervention group and the comparison group was no longer present, and statistical analyses of the whole dataset did not disclose differences $(\mathrm{P}=0.49$ on the generalized Wilcoxon test), nor did a life table analysis of mortality $(\mathrm{P}=0.92$ on the generalized Wilcoxon test).

Table 2. Cox proportional hazards regression analysis of days on study before death or long-term placement in nursing home, by age, gender and intervention.

\begin{tabular}{lcccc}
\hline & Coeff. & SE & Coeff/SE & Odds ratio \\
\hline Age (per 10 years) & 0.77 & 0.29 & 2.69 & 2.2 \\
Gender* $^{*}$ & -0.03 & 0.37 & -0.09 & 1.0 \\
Intervention $^{\#}$ & 0.72 & 0.36 & 2.01 & 2.1 \\
\hline
\end{tabular}

* Gender: $1=$ males, 2 = females

\# Intervention: 1 = intervention group, 2 = comparison group 


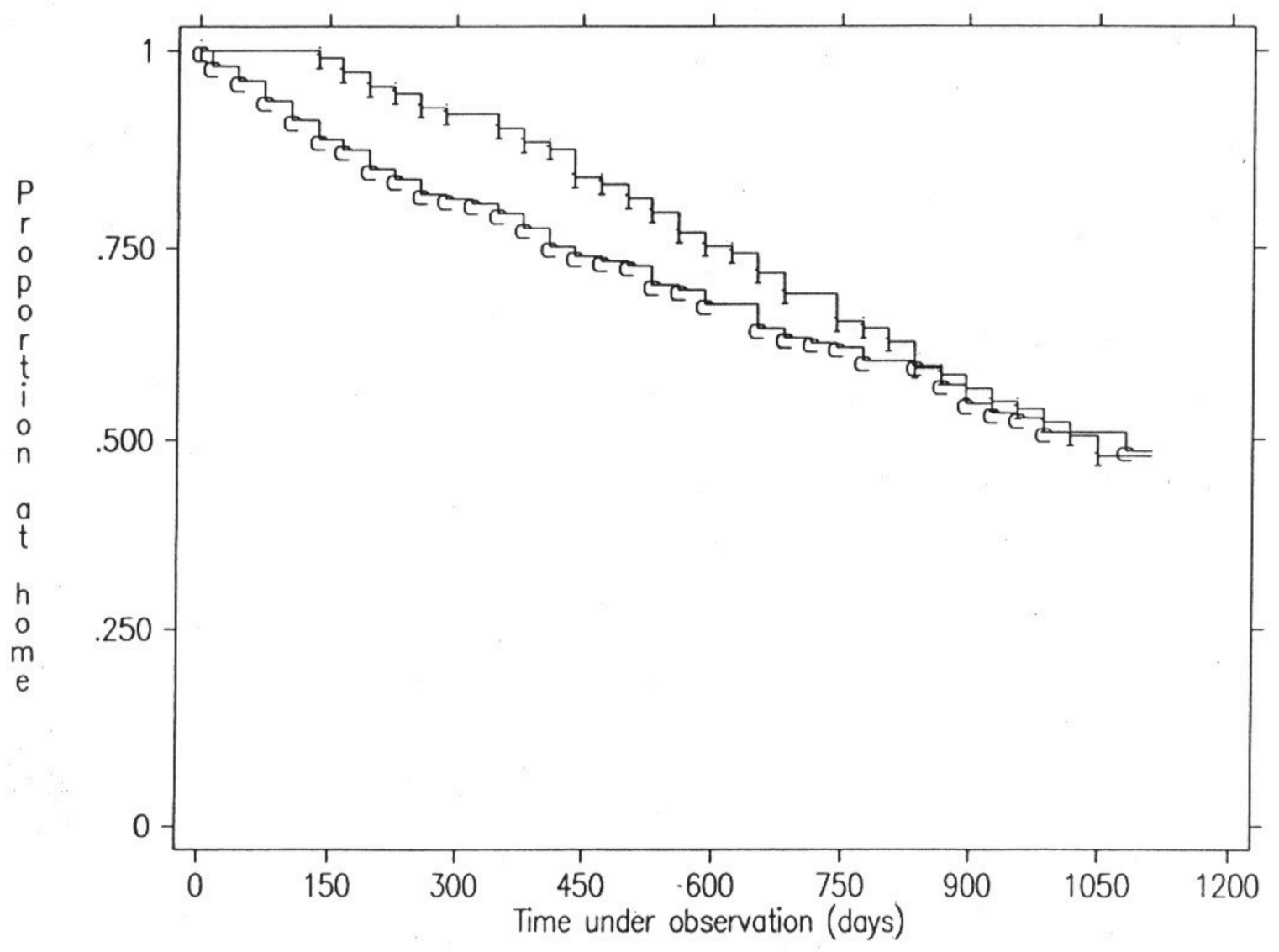

Figure 1. Life-table of days on study before death or placement in nursing home. $\mathrm{i}=$ intervention group; $\mathrm{c}=$ comparison group.

At the end of the study, support services were used to the same extent by intervention clients and comparison clients, except for "meals on wheels", which was more frequently used by the intervention clients. These clients had also been more frequently admitted to hospital than the controls $(\mathrm{P}<0.05)$ (Table 3$)$, and spent more days as hospital in-patients (mean 23.3 versus 20.3, $\mathrm{P}=0.02$ on Mann-Whitney testing). This difference persisted after adjustment for differences in age by analysis of variance $(\mathrm{P}=0.03)$. Only 15 out of a total of 188 referrals to hospital in the intervention group were initiated by the study doctor.

\section{DISCUSSION}

The primary aim of the study was to evaluate whether referral by home helps directly to a hospital-based general practitioner can help elderly people to live longer at home. The results are equivocal.

The life-table analysis (Figure 2) disclosed an initial positive trend, which lasted for at least a year and was statistically significant after adjusting for baseline differences in age and gender. The loss of effect towards the end of the study could have many reasons.
One might be diminishing enthusiasm among the home helps. Another might be the competing factors that can operate when elderly people are no longer able to stay at home, not all of which are potentially reversible, e.g. advanced ageing, disseminated cancers and severe heart failure. The training received by all home helps would be expected to increase the referrals to medical care for both groups and make an altered secular trend in the comparison group. The real intervention was that the home helps in the intervention group were told to monitor clients and contact the study doctor. Unfortunately the referral rate to GPs in the comparison group is unknown and the total effect of training home helps as indicated is not studied here.

The study demonstrates the methodological problem of conducting a controlled trial where the randomization units are the organizational units of the home helps and the observational units are their clients. Today, home helps in Norway tend to be organized together with the home nurses, and this makes it impossible to randomize within such groups when the objective is to study the provision of services. In a study like this, being carried out in a single county, randomization of so few units is ineffective in ensuring comparable groups. Here, this resulted in the intervention group 
being older than the control group. The effect of intervention on the main outcome variable was restricted to the group with on-site home help and home nursing. However, this group also had more referrals to the study doctor, and it is impossible to conclude whether the observed effect was caused by the intervention model or the on-site services provided for this group.

Table 3. Hospital admissions in the two groups. Chi square for linear trend of proportions $=3.85$ on 1 d.f., $\mathrm{P}<0.05 ; \mathrm{P}<0.05$ still after adjustment for group differences in age $(75-79,80-84,85-90,90+$ years $)$ by polychotomous logistic regression. Cox proportional hazards regression analysis of days on study before death or longterm placement in nursing home, by age, gender and intervention.

\begin{tabular}{lrrrrr}
\hline $\begin{array}{l}\text { Number of } \\
\text { admissions }\end{array}$ & \multicolumn{2}{c}{$\begin{array}{c}\text { Intervention } \\
\text { group }\end{array}$} & \multicolumn{3}{c}{$\begin{array}{c}\text { Control } \\
\text { group }\end{array}$} \\
\hline 0 & 35 & $(31.0)$ & & 67 & $(41.6)$ \\
$1-2$ & 48 & $(42.5)$ & 68 & $(42.2)$ \\
$3-5$ & 25 & $(22.1)$ & 19 & $(11.7)$ \\
$6+$ & 4 & $(3.6)$ & 7 & $(4.4)$ \\
\hline
\end{tabular}

* No data for one subject.

Only $5.5 \%$ of the referrals did not result in diagnosis, giving a low and acceptable false positive rate. The false negative rate is unknown since the clients are not medically monitored independently of the home helps, but probably lower than in the comparison group because referrals are specifically asked for. Agreement between the doctor's diagnoses and the home helps' referrals of subjects with suspected infections and stroke was good (Table 1). General loss of function and mental symptoms and cognitive impairment were frequent causes of referral, indicating that the home helps were aware of functional and mental impairment. Most of these referrals were caused by detectable diseases, demonstrating the importance of observing functional ability and not only specific symptoms when the objective is to detect diseases in elderly people.

The current study indicates that health surveillance of elderly people by home helps and direct referral to a hospital-based general practitioner may help to keep elderly people at home longer, but provides no definite evidence of it. It also demonstrates that home helps can detect and communicate to a doctor functional decline and important clinical manifestations of disease among their elderly clients. The cost of such an intervention system is not calculated, but is probably low because it is implemented in already existing services.

An important question is whether it is worthwhile to plan and finance a large-scale randomized trial of the usefulness of such a referral system. Owing to changes in training schemes, Norwegian home helps will in the future receive more medical education, hopefully encompassing the essential presentations of disease in the elderly. By detecting conditions that require medical treatment, such an intervention advances the standard of care. It is therefore ethical practice to train home helps and organize the doctor in charge to urge home helps to make referrals and assess the patients. An alternative to a properly randomized trial would be to stimulate better communication between the home helps, the home nurses and the general practitioners to ensure that diagnostic measures are initiated when the home helps observe a decline in functional level or clinical signs indicative of deteriorating health. I then recommend that this standard should be adopted straight away.

\section{ACKNOWLEDGEMENTS}

This study was made possible by grants from the Norwegian National Health Organization and the Norwegian National Board of Health. I would also thank the home helps and the elderly persons who participated in the study, and Professor Knut Laake and Dr. Torgeir Bruun Wyller for their helpful criticism of an early draft of the article.

\section{REFERENCES}

1. Brocklehurst JC. Textbook of Geriatric Medicine and Gerontology. Edinburgh: Churchill Livingstone, 1994.

2. Stuck AE, Siu AL, Wieland GD, Adams J, Rubenstein LZ. Comprehensive geriatric assessment: a metaanalysis of controlled trials. Lancet 1993; 342: 1032-1036.

3. Pathy MSJ, Bayer A, Harding K, Dibble A. Randomised trial of case finding and surveillance of elderly people at home. Lancet 1992; 340: 890-893.

4. Hendriksen C, Lund E, Strømgård E. Consequences of assessment and intervention among elderly people: a three year randomised controlled trial. BMJ 1984; 289: 1522-1524.

5. Hansen FR, Spedtsberg K, Schroll M. Geriatric follow-up by home visits after discharge from hospital: a randomised controlled trial. Age Ageing 1992; 21: 445-450.

6. Williamson J. Screening, surveillance and case-finding. In: Arie T, ed. Health Care of the Elderly. London: Croom Helm, 1981: 194-213. 
7. Ranhoff AH, Laake K. Health and functioning among elderly recipients of home help in Norway. Health Soc Care Community 1995; 3: 115-123.

8. Ranhoff AH. Activities of daily living, cognitive impairment and other psychological symptoms among elderly recipients of home help. Health Soc Care Community 1997; 5: 147-152.

9. Thorslund M, Norstrom T, Wernberg K. The utilization of home help in Sweden: a multivariate analysis. Gerontologist 1991; 1: 116-119.

10. Statistics Norway: Statistical Yearbook 1985-93. Oslo: Statistics Norway, 1994.

11. Mahoney FI, Barthel DW. Functional evaluation: the Barthel index. Md State Med J 1965; 14: 61-65.

12. Hughes CP, Berg L, Danziger WL, Coben LA, Martin RL. A new clinical scale for the staging of dementia. Br J Psychiatry 1982; 140: 566-572.

13. Ranhoff AH. Reliability of nursing assistants' observation of functioning and clinical symptoms and signs. Aging Clin Exp Res 1997; 9: 378-380.

14. Arcand M, Williamson J. An evaluation of home visiting of patients by physicians in geriatric medicine. $B M J$ 1981; 283: 718-720.

15. Manual of the International Statistical Classification of Diseases, Injuries and Causes of Death (ICD-9). Oslo: Statistics Norway, 1986.

16. Dixon WJ. BMDP Statistical Software. Berkeley, CA: University of California Press, 1992. 